\title{
Evaluation of Short-term Outcomes of Tracheostomy Procedures in a NICU Population with High Ventilator Settings
}

Authors: Laura Banks ${ }^{1}$, Noah Worobetz ${ }^{1,2}$, Erin Hamersley, DO, LCDR, MC, USN ${ }^{1,3}$, Amanda Onwuka PhD MPH ${ }^{4}$, Edward Shepherd MD ${ }^{2,5}$, Gregory Wiet MD ${ }^{1,2,6}$

Institutions: ${ }^{1}$ Department of Otolaryngology - Head and Neck Surgery, Nationwide Children's Hospital, Columbus, Ohio, 43205 USA; ${ }^{2}$ The Ohio State University College of Medicine, Columbus, Ohio, 43210 USA; ${ }^{3}$ Naval Medical Leader and Professional Development Command ${ }^{4}$ Center for Surgical Outcomes Research, Nationwide Children's Hospital, Columbus, Ohio, USA, ${ }^{5}$ Department of Neonatology, Nationwide Children's Hospital, Columbus, Ohio USA, ${ }^{6}$ Department of Otolaryngology - Head and Neck Surgery, The Ohio State University Wexner Medical Center, Columbus, Ohio, 43212, USA

Laura Banks: assisted in design of the project, wrote the article, presenter at AAO-HNSF 2020 Virtual Annual Meeting \& OTO Experience

Noah Worobetz, BS: assisted in design of the project, collected data, revised article

Erin Hamersley, DO: assisted in design of project, revised article

Amanda Onwuka, PhD: analyzed data, provided results and tables, and revised article

Edward Shepherd, MD: established the original concept and design of the project, revised article, provided interpretation of data

Gregory Wiet, MD: established the original concept and design of the project, revised article, provided interpretation of data

Date: October 24, 2020 
Presented at: AAO-HNSF 2020 Virtual Annual Meeting \& OTO Experience; On-Demand Virtual Experience; September 13, 2020

\section{Funding: N/A}

Conflicts of Interest: The authors have no conflicts of interests to disclose.

Corresponding Author: Gregory Wiet, MD, FACS, FAAP

Departments of Pediatric Otolaryngology - Head and Neck Surgery, Nationwide Children's Hospital, 700 Children's Drive, Columbus, OH, 43205

Email: Gregory.Wiet@nationwidechildrens.org, Phone: 614-722-6600, Fax: 614-722-6609

\section{Acknowledgments: None}

Key Words: tracheostomy tube placement, tracheotomy, ventilator settings, otolaryngology, neonatology, pediatric

"The views expressed in this article reflect the results of research conducted by the author and do not necessarily reflect the official policy or position of the Department of the Navy, Department of Defense, nor the United States Government."

"I am a military service member or federal/contracted employee of the United States government. This work was prepared as part of my official duties. Title 17 U.S.C. 105 provides that 'copyright protection under this title is not available for any work of the United States Government.' Title 17 U.S.C. 101 defines a U.S. Government work as work prepared by a military service member or employee of the U.S. Government as part of that person's official duties." 
The study protocol was approved by the Nationwide Children's Hospital Institutional Review Board in compliance with all applicable federal regulations governing the protection of human subjects 


\section{$\underline{\text { Abstract }}$}

Objective: Investigation of whether tracheostomy placement in infants requiring high ventilator pressure is safe and effective.

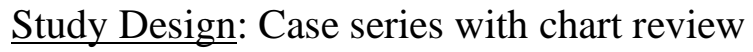

Setting: Tertiary children's hospital

Methods: Fifty ventilator-dependent neonatal intensive care unit patients who underwent tracheotomy from 2009 -2018 were included. Patients requiring high ventilator pressures were compared to those requiring low ventilator pressures. Demographics, comorbidities, surgical and clinical data were recorded.

Results: Thirty-two percent $(n=16)$ had low ventilator settings at the time of tracheostomy tube placement, and $68 \%(n=34)$ had high ventilator settings. The median peak inspiratory pressure of the high ventilator group was $29.5 \mathrm{~cm} \mathrm{H}_{2} \mathrm{O}$, positive end-expiratory pressure (PEEP) was $8 \mathrm{~cm}$ $\mathrm{H}_{2} \mathrm{O}$, mean airway pressure was $13 \mathrm{~cm} \mathrm{H}_{2} \mathrm{O}$, pressure support (PS) was $14 \mathrm{~cm} \mathrm{H}_{2} \mathrm{O}$, PS above PEEP was $6 \mathrm{~cm} \mathrm{H}_{2} \mathrm{O}$, and inspiratory time was 0.65 seconds. The high ventilator cohort had a higher median age at the time of surgery compared to the low ventilator group $(p=0.02)$. Female patients were more likely to have high ventilator settings $(\mathrm{p}=0.02)$. There were no intraoperative complications or deaths within the first 7 days of tracheostomy tube placement. Pneumonia incidence and rate of mortality during admission did not vary by ventilator settings (p $=0.92, \mathrm{p}=0.94$, respectively)

Conclusion: Few differences in tracheostomy tube placement outcomes were observed for patients with high ventilator settings compared to low ventilator settings. This data demonstrates that patients requiring high ventilator pressures can benefit from tracheostomy tube placement with no additional short-term risks. 


\section{Introduction}

Prematurity is one of the most common complications of pregnancy, and rates have remained high in the United States despite decades of preventative efforts. ${ }^{1}$ Most prematurely born infants will survive without significant impairment, however rates of morbidity and mortality increase markedly with decreasing gestational age. Bronchopulmonary dysplasia (BPD) is the most common complication of prematurity, affecting around $20 \%$ of very low birthweight (VLBW,

less than $1500 \mathrm{~g}$ ) infants. ${ }^{2} \mathrm{~A}$ fraction of these infants require prolonged mechanical ventilation to survive, however this predisposes them to a markedly increased risk for cognitive development delays and airway stenosis. ${ }^{3}$

To help prevent these complications, tracheostomies are often performed when there is a need for long term ventilation. Although there is relatively little evidence in the literature to guide care, placement of a tracheostomy tube (TT) is thought to allow for improved chronic disease management, nutrition, growth, comfort, and opportunity for vocalization with speaking valve use. ${ }^{3,4}$ Additionally, TT placement is thought to improve work of breathing and decrease length of hospital stay, need for sedation, and systemic corticosteroid exposure..$^{3,5}$

Rates of TT placement are highly variable across centers suggesting that there may be perceived barriers to performing a tracheostomy. ${ }^{6}$ One potential barrier is the perception that infants requiring higher ventilator pressures are not suitable candidates for TT placement. Our comprehensive center for BPD (CCBPD) is a standalone, referral-based unit devoted to the care of infants with BPD and thus has substantial experience placing TTs in infants with the most severe forms of BPD. The goal of our study is to investigate whether tracheostomy placement in 
infants requiring high ventilator pressure is safe and effective by evaluating short-term outcomes within 7 days after TT placement.

\section{Methods:}

We conducted a case series with chart review at a large academic tertiary pediatric hospital from 2009 to 2018. Ventilator-dependent neonatal intensive care unit (NICU) patients less than 1 year old chronologically at time of trach placement were included in the study. Patients who were not located in the neonatal ICU, did not receive tracheostomy, or greater than one year old chronologically were excluded from the study. Medical records were reviewed for demographic information, gestational age, age at time of TT placement, and concurrent procedures. Preoperative diagnoses such as pneumonia and comorbidities were also recorded. This study was approved by the Nationwide Children's Hospital Institutional Review Board.

High ventilator pressure was the primary independent variable of interest, and was defined as having one of the following at the time of TT placement: peak inspiratory pressure (PIP) greater than $25 \mathrm{~cm} \mathrm{H}_{2} \mathrm{O}$, positive end-expiratory pressure (PEEP) greater than $6 \mathrm{~cm} \mathrm{H}_{2} \mathrm{O}$, or mean airway pressure (MAP) greater than $10 \mathrm{~cm} \mathrm{H}_{2} \mathrm{O}$. There is no literature available to our knowledge that describes average ventilator settings for infants in the NICU. Thus, we examined articles describing ventilator settings at the time of extubation attempt, and noted ranges of PIP of 13-24 $\mathrm{cm} \mathrm{H}_{2} \mathrm{O}$, PEEP of 4-6 $\mathrm{cm} \mathrm{H}_{2} \mathrm{O}$, and MAP of 5-8 $\mathrm{cm} \mathrm{H}_{2} \mathrm{O} .^{7,8,9}$ Based on these data and consensus within our group of Neonatologists, we determined that PIP greater than $25 \mathrm{~cm} \mathrm{H}_{2} \mathrm{O}$, PEEP greater than $6 \mathrm{~cm} \mathrm{H}_{2} \mathrm{O}$, or mean airway pressure greater than $10 \mathrm{~cm} \mathrm{H}_{2} \mathrm{O}$ were "high ventilator settings." Among those with high settings, we performed sensitivity analyses for 
patients with a PIP, PEEP or MAP above the $80^{\text {th }}$ percentile and arbitrarily defined those above this cutoff as "extremely high." Patients requiring extremely high ventilator pressure had at least one of the following measurements: PIP greater than $37 \mathrm{~cm} \mathrm{H}_{2} \mathrm{O}$, PEEP greater than $8 \mathrm{~cm} \mathrm{H}_{2} \mathrm{O}$ and MAP greater than $15.5 \mathrm{~cm} \mathrm{H}_{2} \mathrm{O}$.

Short-term outcomes of tracheostomy tube placement were evaluated for children with low versus high ventilator pressures. Short-term outcomes included intraoperative complications, pneumonia incidence, and in-hospital mortality within 7 days after TT placement. Changes in ventilator settings before the tracheotomy to one week after the tracheotomy were also recorded.

To describe continuous variables, medians and interquartile ranges are presented, and proportions describe categorical variables. Differences in categorical variables were evaluated with chi-squared tests, and differences in continuous variables were evaluated with t-tests and Wilcoxon-Mann-Whitney tests. Analyses were conducted in SAS Enterprise Version 8.1 and statistical significance was evaluated at the 0.05 alpha level.

\section{$\underline{\text { Results }}$}

Fifty ventilator-dependent NICU patients under 1 year underwent tracheostomy tube placement between 2009-2018. Thirty-two percent $(n=16)$ of these infants had low ventilator settings at the time of TT placement, and 68\% $(n=34)$ had high ventilator settings (Table 1). The most common indication for tracheostomy overall was respiratory failure or distress (70\%), followed by BPD $(20 \%)$ and subglottic stenosis $(16 \%)$. However, BPD was an indicator for tracheostomy more frequently in the high ventilator $(\mathrm{HV})$ cohort $(27 \%, \mathrm{p}=0.04)$. The median PIP of the HV group 
was $29.5 \mathrm{~cm} \mathrm{H}_{2} \mathrm{O}$, PEEP was $8 \mathrm{~cm} \mathrm{H} \mathrm{H}_{2} \mathrm{O}$, MAP was $13 \mathrm{~cm} \mathrm{H} \mathrm{H}_{2} \mathrm{O}$, pressure support (PS) was $14 \mathrm{~cm}$ $\mathrm{H}_{2} \mathrm{O}$, PS above PEEP was $6 \mathrm{~cm} \mathrm{H} \mathrm{H}_{2} \mathrm{O}$, and inspiratory time was 0.65 seconds. Fraction of inspired oxygen $\left(\mathrm{FiO}_{2}\right)$ was a median of 0.32 in the $\mathrm{LV}$ cohort and 0.4 in the $\mathrm{HV}$ cohort. Neither FiO2 nor respiratory rate in breaths per minute were significantly different between groups.

The HV cohort had a higher median age at the time of surgery at 20.6 weeks compared to the low vent $(\mathrm{LV})$ group at 9.3 weeks $(\mathrm{p}=0.02)$. The gestational age and weight did not significantly differ between groups $(\mathrm{p}=0.11, \mathrm{p}=0.60$ respectively). Female patients were more likely to have high ventilator settings $(\mathrm{p}=0.02)$. Female patients were not significantly older than male patients at the time of tracheostomy $(\mathrm{p}=0.40)$, and there were no differences weight between female and male patients. Race and ethnicity did not vary significantly between groups. There were no differences observed between cohorts based on incidence of concurrent procedures, preoperative pneumonia or pre-operative syndromes. The HV group had a longer median duration of intubation at 137 days compared to the LV group at 61 days $(\mathrm{p}=0.02)$.

A Bivona® tight to the shaft ${ }^{\mathrm{TM}}$ (Smiths Medical ASD, Inc. Gary, IN) cuffed tracheostomy tube was used in all TT procedures regardless of preoperative ventilation pressure. The postoperative changes in ventilator settings for each group were recorded (Table 2). The PEEP increased by 1 $\mathrm{cm} \mathrm{H} 2 \mathrm{O}$ for the LV group, while the PEEP remained the same for the HV group $(\mathrm{p}=0.02)$. The PS did not change on average in the LV group, while the PS increased by 1.5 in the HV group $(\mathrm{p}=0.04)$. The PS above PEEP decreased by $0.5 \mathrm{~cm} \mathrm{H}_{2} \mathrm{O}$ for the $\mathrm{LV}$ group, and increased by 2 $\mathrm{cm} \mathrm{H}_{2} \mathrm{O}$ for the $\mathrm{HV}$ group $(\mathrm{p}=0.03$ ). All other ventilator settings did not significantly change between groups. 
Additionally, evaluation of whether the differences pre- and post-tracheostomy in each group differed significantly was performed. None of the ventilator settings changed significantly in the LV group. However, changes in ventilator settings pre- and post-tracheostomy were observed in the $\mathrm{HV}$ group. Median $\mathrm{FIO}_{2}$ was 40 pre-tracheostomy compared to 35 post-tracheostomy $(\mathrm{p}=0.03)$. Median PS was 14 pre-tracheostomy compared to 10 post-tracheostomy $(\mathrm{p}=0.01)$. Finally, PS above PEEP was 6 pre-tracheostomy compared to 2 post-tracheostomy ( $\mathrm{p}=0.01)$.

A thorough review of both operative notes and anesthesia records revealed no intraoperative complications in either group. No deaths were observed within the first 7 days of TT placement. Pneumonia incidence postoperatively was $18 \%$ in the HV cohort and $19 \%$ in the LV cohort and did not vary between groups $(\mathrm{p}=0.92)$. Similarly, the rate of mortality during admission beyond the 7-day window of examination was $16 \%$ and did not vary between ventilator setting groups $(\mathrm{p}=0.94)$. The most common cause of death during the admission was respiratory failure $(\mathrm{n}=3)$, but cardiovascular conditions, trauma, congenital and chromosomal conditions were also observed. Long-term mortality was increased in the HV cohort past our window of examination with $41 \%$ mortality in the HV group and $13 \%$ mortality in the low vent group $(p=0.04)$.

Sensitivity analyses among children with extremely high ventilator settings were also conducted to assess if differences were more apparent in this group (Table 3). Twenty-three children (46\%) had at a PIP, PEEP or MAP at or exceeding the $80^{\text {th }}$ percentile. We observed no differences in mortality during the admission or pneumonia incidence among children at the $80^{\text {th }}$ percentile or higher compared to all others ( $\mathrm{p}=0.80$ and $0=0.40$, respectively). Further, we observed no 
differences in changes in ventilator setting postoperatively in the extremely high ventilator settings group, with the exception of postoperative PIP. Children with extremely high ventilator settings tended to have an increase in PIP of $1 \mathrm{~cm} \mathrm{H}_{2} \mathrm{O}$ one week postop, compared to other children who had had a median decrease of $2 \mathrm{~cm}(\mathrm{p}=0.03)$.

\section{Discussion}

Tracheostomy tube placement is a common procedure performed for premature infants requiring respiratory assistance. ${ }^{3}$ A perceived barrier to performing a tracheostomy is a patient's need for $\mathrm{HV}$ pressure. It is often assumed that neonates requiring high ventilator pressure will have higher complication rates during and after TT placement. ${ }^{4}$ Previous studies report an increased incidence of air leaks with high PIP and MAP $\left(>12 \mathrm{~cm} \mathrm{H}_{2} \mathrm{O}\right)$, thus preventing sufficient lung expansion. ${ }^{10}$ Upon thorough literature review, very little further information has been published to address the validity of this concern. Drawing upon clinical experience, a particular challenging aspect to these cases is maintaining high ventilator pressures during anesthesia with an open airway. In an effort to determine if placement of the TT tube is feasible, short-term outcomes of tracheostomy tube placement were evaluated for children with LV versus HV pressures.

The analysis of preoperative characteristics show that female patients were more likely to have HV settings. After finding no significant differences in age or weight between male and female patients, we believe this difference is an artifact of the relatively small numbers in our cohorts. Additionally, HV patients had a significantly higher median age at the time of surgery and had a longer median duration of intubation. This result is expected for patients with HV settings as it 
inevitably takes longer to wean these patients from support in order to place the tracheostomy tube.

Although there were statistical changes in a variety of ventilator settings before and after TT placement, we believe that the absolute changes involved are clinically insignificant. Overall, we would argue that the relatively small changes in postoperative ventilator support provide evidence that placement of TT in patients is both feasible and safe.

The main objective of our study was to examine the short-term outcomes of TT placement in ventilator-dependent neonatal ICU patients requiring high ventilator pressures. Within the first 7 days of TT placement, no groups had intraoperative complications or deaths. Our study therefore demonstrates that placement of the tracheostomy, regardless of ventilator pressure, did not result in adverse short-term outcomes. Previous studies indicate that children with TT placement are at an increased risk for respiratory infections, such as pneumonia, by introducing a new site of entry for bacteria into the lower airway. ${ }^{11}$ To demonstrate that patients requiring HV pressure are at no greater risk for pneumonia development in the short-term compared to patients requiring LV pressure, we included pneumonia incidence as a major outcome and found no difference between groups in pneumonia development. Mortality during admission beyond the 7-day window of examination was included after finding very few differences in short-term outcomes. Again, mortality during admission did not differ between groups, demonstrating that placement of the tracheostomy in patients requiring $\mathrm{HV}$ pressure posed no observed risks to patients. Therefore, patients requiring HV pressures can undergo TT placement to benefit from reduced 
intubation time, which can reduce the risk of intubation related laryngeal trauma, length of the hospital stay and need for sedation. ${ }^{12}$

Since very few differences were observed between the LV and HV cohorts, sensitivity analyses among children with extremely high ventilator (EHV) settings were conducted to determine if differences were more apparent in this group. Patients with PIP, PEEP, or MAP exceeding the $80^{\text {th }}$ percentile still showed no differences in pneumonia incidence or mortality during admission compared to all others. Therefore, patients requiring EHV settings were not at increased risk for short-term mortality or pneumonia. Additionally, we observed no differences in changes in ventilator setting postoperatively in the EHV settings group, with the exception of postoperative PIP. Although patients with EHV settings required an increase in PIP, the lack of significant changes with all other ventilator settings likely does not suggest that the EHV cohort required further dependency on the ventilator.

By demonstrating that placement of a tracheostomy did not lead to increased intraoperative complications or death, post-operative pneumonia or mortality during admission, we concluded that HV pressure requirements did not pose additional risk for patients. Therefore, the assumed barriers associated with placing a TT tube in a patient with HV pressure are not supported by our data. Thus, the concern for potential leaks and insufficient lung expansion can be refuted as there was no difference in negative short-term outcomes when compared to the LV patients. Instead, HV patients can benefit from tracheostomy tube placement to avoid long-term sedation, which can lead to cognitive delays. ${ }^{3}$ The patients benefit from the opportunity to remain awake and 
interact with the environment and caretakers. ${ }^{3}$ Length of hospital, stay and systemic corticosteroid exposure can be decreased with the placement of a TT as well. ${ }^{3,5}$

The study itself has many limitations. First, being a case series with chart review limits the ability to properly gather all data points that could have been recorded. Additionally, the study is

limited by the relatively small numbers in each cohort. Finally, this study is also limited by being conducted at a single pediatric tertiary hospital. Further multicenter, prospective studies can help alleviate these limitations.

An increase in long-term mortality past our window of examination for patients requiring HV pressure is expected due to the influence of many confounding factors that are not necessarily related to the tracheostomy itself. These conditions also might have led to the placement of the TT in the first place. However, the tracheostomy might have had adverse effects that led to worsening respiratory conditions or infections. More insight to the relationship between placement of the tracheostomy and the cause of death must be investigated to show any further connection between the two. Lastly, the long-term outcomes will be evaluated in a future study to better understand the long-term effects of TT on patients requiring HV pressure.

\section{Conclusion}

With the exception of mild changes in ventilator pressures, few differences in TT placement outcomes were observed for children with high ventilator settings compared to low ventilator 
settings. This data demonstrates that patients requiring HV pressures can benefit from the advantages of TT placement with no additional short-term risks. 


\section{Acknowledgements}

Thank you to Weston Niermeyer BS for assisting in the design of the study. 


\section{References}

1. Shapiro-Mendoza CK, Lackritz EM. Epidemiology of late and moderate preterm birth. Semin Fetal and Neonatal Med. 2012; 17(3):120-125.

2. Lee HC, Liu J, Profit J, Hintz SR, Gould JB. Survival without major morbidity among very low birth weight infants in Califor- nia. Pediatrics. 2020;146(1):e20193865.

3. Overman AE, Liu M, Kurachek SC, et al. Tracheostomy for infants requiring prolonged mechanical ventilation: 10 years’ experience. Pediatrics. 2013;131(5):e1491-e1496.

4. Mandy G, Malkar M, Welty SE, et al. Tracheostomy placement in infants with bronchopulmonary dysplasia: safety and out- comes. Pediatr Pulmonol. 2013;48(3):245249.

5. Watters KF. Tracheostomy in infants and children. Respir Care. 2017;62(6):799-825.

6. Murthy K, Porta NFM, Lagatta JM, et al. Inter-center variation in death or tracheostomy placement in infants with severe bronchopulmonary dysplasia. J Perinatol. 2017;37(6):723-727.

7. Dassios T, Kaltsogianni O, Greenough A. Relaxation rate of the respiratory muscles and prediction of extubation outcome in pre- maturely born infants. Neonatology. 2017;112(3):251-257.

8. Mhanna MJ, Iyer NP, Piraino S, Jain M. Respiratory severity score and extubation readiness in very low birth weight infants. Pediatr Neonatol. 2017;58(6):523-528.

9. Nelin L, Shepherd, Alexander, Kuehne, Reber. The FiO2 is asso- ciated with the successful extubation of mechanically ventilated neonates. Res Reports Neonatol. 2011;1:55-59. 
10. Fraser D. Complications of positive pressure ventilation. In: Fraser D, ed. Acute respiratory care of the neonate. 3rd ed. NICU Ink Book Publishers; 2012;195-238.

11. Cline JM, Woods CR, Ervin SE, Rubin BK, Kirse DJ. Surveil- lance tracheal aspirate cultures do not reliably predict bacteria cultured at the time of an acute respiratory infection in children with tracheostomy tubes. Chest. 2012;141(3):625-631.

12. Ertugrul I, Kesici S, Bayrakci B, Unal OF. Tracheostomy in pediatric intensive care unit: when and where? Iran J Pediatr. 2016;26(1):e2283. 


\begin{tabular}{|c|c|c|c|c|c|c|c|}
\hline \multicolumn{8}{|c|}{ Table 1: Preoperative Characteristics in NICU Infants Undergoing Tracheostomy by Ventilator Settings } \\
\hline & \multicolumn{2}{|c|}{ Total } & \multicolumn{2}{|c|}{ Low } & \multicolumn{2}{|c|}{ High } & \multirow[t]{2}{*}{ p value } \\
\hline & $\begin{array}{c}\mathrm{N} \\
\text { (Median) }\end{array}$ & $\%(\mathrm{Q} 1, \mathrm{Q} 3)$ & $\begin{array}{c}\mathrm{N} \\
\text { (Median) }\end{array}$ & $\%(\mathrm{Q} 1, \mathrm{Q} 3)$ & $\begin{array}{c}\mathrm{N} \\
\text { (Median) }\end{array}$ & $\%(\mathrm{Q} 1, \mathrm{Q} 3)$ & \\
\hline $\mathrm{N}$ & 50 & $100 \%$ & 16 & $32 \%$ & 34 & $68 \%$ & \\
\hline Age (weeks) & 17.4 & $9.3,26.6$ & 9.3 & $6.3,20.5$ & 20.6 & $13.1,27.3$ & 0.02 \\
\hline Vent Settings at the time of trach & & & & & & & \\
\hline $\mathrm{PIP}^{1}$ & 27 & 23,32 & 21.5 & $20,23.5$ & 29.5 & 27,40 & \\
\hline $\mathrm{PEEP}^{2}$ & 7 & 6,8 & 6 & 5,7 & 8 & 6,8 & 0.01 \\
\hline $\mathrm{MAP}^{3}$ & 11.5 & 10,15 & 9 & 8,10 & 13 & 11,16 & $<0.0001$ \\
\hline $\mathrm{FIO}^{4}$ & 40 & 31,50 & 32 & 25,41 & 40 & 34,60 & 0.13 \\
\hline $\mathrm{PS}^{5}$ & 13 & 10,15 & 10 & 6,13 & 14 & 12,17 & 0.01 \\
\hline PS above PEEP 6 & 6 & 2,8 & 5 & 0,6 & 6 & 6,10 & 0.04 \\
\hline Rate Breaths per Minute & 25 & 18,30 & 30 & $22.5,30$ & 20 & 18,30 & 0.13 \\
\hline Inspiratory Time $(\mathrm{sec})$ & 0.6 & $0.4,0.8$ & 0.4 & $0.35,0.475$ & 0.65 & $0.5,0.8$ & 0.004 \\
\hline Gestational age at birth (weeks) & 31.5 & 26,34 & 33.5 & $27.5,36.0$ & 29.5 & 25,34 & 0.11 \\
\hline Weight at the time of trach $(\mathrm{g})$ & 3958 & 2920,4710 & 3956 & 3047,4080 & 4095 & 2920,4816 & 0.60 \\
\hline Race/Ethnicity & & & & & & & 0.08 \\
\hline $\mathrm{NH}^{7}$ White & 33 & $66 \%$ & 10 & $63 \%$ & 23 & $68 \%$ & \\
\hline $\mathrm{NH}^{7}$ Black & 11 & $22 \%$ & 2 & $13 \%$ & 9 & $26 \%$ & \\
\hline Hispanic & 1 & $2 \%$ & 0 & $0 \%$ & 1 & $3 \%$ & \\
\hline Other & 5 & $10 \%$ & 4 & $25 \%$ & 1 & $3 \%$ & \\
\hline Sex & & & & & & & 0.02 \\
\hline Male & 29 & $58 \%$ & 13 & $81 \%$ & 16 & $47 \%$ & \\
\hline Female & 21 & $42 \%$ & 3 & $19 \%$ & 18 & $53 \%$ & \\
\hline Concurrent procedures & & & & & & & \\
\hline None & 14 & $29 \%$ & 4 & $25 \%$ & 10 & $29 \%$ & 0.75 \\
\hline $\mathrm{DLB}^{8}$ & 33 & $66 \%$ & 11 & $69 \%$ & 22 & $65 \%$ & 0.78 \\
\hline Transection of thyroid isthmus & 1 & $2 \%$ & 0 & $0 \%$ & 1 & $3 \%$ & 0.49 \\
\hline Flexible Tracheoscopy & 3 & $6 \%$ & 1 & $6 \%$ & 2 & $6 \%$ & 0.96 \\
\hline Dilation & 2 & $4 \%$ & 0 & $0 \%$ & 2 & $6 \%$ & 0.32 \\
\hline Nasal endoscopy & 2 & $4 \%$ & 1 & $6 \%$ & 1 & $3 \%$ & 0.58 \\
\hline Laryngoplasty & 1 & $2 \%$ & 1 & $6 \%$ & 0 & $0 \%$ & 0.14 \\
\hline Pre-operative pneumonia & 7 & $14 \%$ & 1 & $6 \%$ & 6 & $18 \%$ & 0.28 \\
\hline Pre-operative diagnosis & & & & & & & \\
\hline Syndromes & 8 & $16 \%$ & 3 & $19 \%$ & 5 & $15 \%$ & 0.72 \\
\hline Craniofacial Abnormalities & 6 & $12 \%$ & 3 & $19 \%$ & 3 & $9 \%$ & 0.31 \\
\hline Airway Abnormalities & 20 & $40 \%$ & 8 & $50 \%$ & 12 & $35 \%$ & 0.32 \\
\hline Pulmonary Conditions & 42 & $84 \%$ & 12 & $75 \%$ & 30 & $88 \%$ & 0.23 \\
\hline Cardiovascular Conditions & 3 & $6 \%$ & 0 & $0 \%$ & 3 & $8 \%$ & 0.29 \\
\hline Other Medical Conditions & 15 & $30 \%$ & 6 & $38 \%$ & 9 & $26 \%$ & 0.43 \\
\hline Duration of Intubation (days) & 122 & 65,186 & 61 & 44,125 & 137 & 92,191 & 0.02 \\
\hline
\end{tabular}

1 peak inspiratory pressure

${ }^{2}$ positive end-expiratory pressure

${ }^{3}$ mean airway pressure

${ }^{4}$ fraction of inspired oxygen

${ }_{6}^{5}$ pressure support

${ }^{6}$ pressure support above positive end-expiratory pressure

${ }^{7}$ non-Hispanic

${ }^{8}$ direct laryngoscopy and bronchoscopy 


\begin{tabular}{|c|c|c|c|c|c|c|c|}
\hline & \multicolumn{7}{|c|}{ Table 2: Outcomes of Tracheostomy by Ventilator Settings } \\
\hline & \multicolumn{2}{|c|}{ Total } & \multicolumn{2}{|c|}{ Low } & \multicolumn{2}{|c|}{ High } & \multirow[t]{2}{*}{ p value } \\
\hline & $\begin{array}{c}\mathrm{N} \\
\text { (Median) }\end{array}$ & $\begin{array}{c}\% \\
(\mathrm{Q} 1, \mathrm{Q} 3)\end{array}$ & $\begin{array}{c}\mathrm{N} \\
\text { (Median) }\end{array}$ & $\begin{array}{c}\% \\
(\mathrm{Q} 1, \mathrm{Q} 3)\end{array}$ & $\begin{array}{c}\mathrm{N} \\
\text { (Median) }\end{array}$ & $\begin{array}{c}\% \\
(\mathrm{Q} 1, \mathrm{Q} 3)\end{array}$ & \\
\hline $\mathrm{N}$ & 50 & $100 \%$ & 16 & $32 \%$ & 34 & $68 \%$ & \\
\hline Mortality (during admission) & 8 & $16 \%$ & 2 & $13 \%$ & 6 & $18 \%$ & 0.94 \\
\hline Mortality (ever) & 16 & $32 \%$ & 2 & $13 \%$ & 14 & $41 \%$ & 0.04 \\
\hline Intraoperative complications & 0 & $0 \%$ & 0 & $0 \%$ & 0 & $0 \%$ & N/A \\
\hline \multicolumn{8}{|l|}{ Changes in ventilatory settings } \\
\hline PIP $^{9}$ & -1 & $-4.0,2.5$ & -1.5 & $-4.0,1.0$ & 0 & $-3.0,3.0$ & 0.53 \\
\hline $\mathrm{PEEP}^{10}$ & 0 & $0,0.5$ & 1 & $0,2.0$ & 0 & 0,0 & 0.02 \\
\hline MAP $^{11}$ & -0.5 & $-2.0,0$ & -0.5 & $-2.0,0$ & -0.50 & $-2.0,0.5$ & 0.61 \\
\hline $\mathrm{FIO} 2^{12}$ & 10 & $-3.0,16.0$ & 5 & $3.0,16.0$ & 12 & $-3.0,15.0$ & 0.81 \\
\hline $\mathrm{PS}^{13}$ & 0 & $0,4.5$ & 0 & $-1.0,0$ & 1.5 & $0,7.0$ & 0.04 \\
\hline PS above PEEP ${ }^{14}$ & 0 & 0,5 & -0.5 & $-1.5,0$ & 2.0 & $0,7.0$ & 0.03 \\
\hline Rate Breaths per Minute & 0 & $0,5.0$ & 3.0 & $0,7.5$ & 0 & $-2.0,4.0$ & 0.22 \\
\hline Inspiratory Time $(\mathrm{sec})$ & 0 & 0,0 & 0 & $-0.05,0$ & 0 & 0,0 & 0.29 \\
\hline Pneumonia incidence & 9 & $18 \%$ & 3 & $19 \%$ & 6 & $18 \%$ & 0.92 \\
\hline
\end{tabular}

${ }^{9}$ peak inspiratory pressure

${ }^{10}$ positive end-expiratory pressure

${ }^{11}$ mean airway pressure

12 fraction of inspired oxygen

13 pressure support

${ }^{14}$ pressure support above positive end-expiratory pressure 


\begin{tabular}{|c|c|c|c|c|c|c|c|}
\hline \multicolumn{8}{|c|}{ Table 3: Outcomes of Tracheostomy by Extremely High Ventilator Settings } \\
\hline & \multicolumn{2}{|c|}{ Total } & \multicolumn{2}{|c|}{ Low } & \multicolumn{2}{|c|}{ High $\left(8^{\text {th }}\right.$ Percentile $)$} & \multirow[t]{2}{*}{ p value } \\
\hline & $\begin{array}{c}\mathrm{N} \\
\text { (Median) }\end{array}$ & $\begin{array}{c}\% \\
(\mathrm{Q} 1, \mathrm{Q} 3)\end{array}$ & $\begin{array}{c}\mathrm{N} \\
\text { (Median) }\end{array}$ & $\begin{array}{c}\% \\
(\mathrm{Q} 1, \mathrm{Q} 3)\end{array}$ & $\begin{array}{c}\mathrm{N} \\
\text { (Median) }\end{array}$ & $\begin{array}{c}\% \\
(\mathrm{Q} 1, \mathrm{Q} 3)\end{array}$ & \\
\hline $\mathrm{N}$ & 50 & $100 \%$ & 27 & $54 \%$ & 23 & $46 \%$ & \\
\hline Mortality (during admission) & 8 & $16 \%$ & 4 & $15 \%$ & 4 & $17 \%$ & 0.80 \\
\hline Mortality (ever) & 16 & $32 \%$ & 6 & $22 \%$ & 10 & $43 \%$ & 0.11 \\
\hline Intraoperative complications & 0 & $0 \%$ & 0 & $0 \%$ & 0 & $0 \%$ & N/A \\
\hline \multicolumn{8}{|l|}{ Changes in ventilatory settings } \\
\hline PIP $^{15}$ & -1 & $-4.0,2.5$ & -2 & $-5.0,2.0$ & 1.0 & $-1.0,3.0$ & 0.03 \\
\hline $\mathrm{PEEP}^{16}$ & 0 & $0,0.5$ & 0 & $-1.0,0$ & 0 & $0,1.0$ & 0.11 \\
\hline MAP $^{17}$ & -0.5 & $-2.0,0$ & 0 & $-2.0,0$ & -1.0 & $-2.0,1.0$ & 0.39 \\
\hline $\mathrm{FIO} 2^{18}$ & 10 & $-3.0,16.0$ & 13.5 & $3.0,52.0$ & 5.0 & $-3.0,13.0$ & 0.14 \\
\hline $\mathrm{PS}^{19}$ & 0 & $0,4.5$ & 0 & $0,3.0$ & 0 & $0,8.0$ & 0.48 \\
\hline PS above PEEP $^{20}$ & 0 & 0,5 & 1.0 & $0,4.0$ & 0 & $0,8.0$ & 0.87 \\
\hline Rate Breaths per Minute & 0 & $0,5.0$ & 0 & $0,7.5$ & 0 & $-2.0,4.0$ & 0.42 \\
\hline Inspiratory Time (sec) & 0 & 0,0 & 0 & $-0.05,0$ & 0 & $0,0.05$ & 0.09 \\
\hline Pneumonia incidence & 9 & $18 \%$ & 6 & $22 \%$ & 3 & $13 \%$ & 0.40 \\
\hline
\end{tabular}

15 peak inspiratory pressure

${ }^{16}$ positive end-expiratory pressure

${ }^{17}$ mean airway pressure

${ }^{18}$ fraction of inspired oxygen

${ }^{19}$ pressure support

${ }^{20}$ pressure support above positive end-expiratory pressure 